\title{
Correction to: Clinical Propedeutics Students' Skills in a Simulation Laboratory
}

\author{
Azucena Maribel Rodríguez - González ${ }^{1,2}$ • Fernando García - Rodríguez ${ }^{3}$ Enrique Adrián Martínez - Cervantes ${ }^{1}$. \\ Gregorio Garza - Garza ${ }^{1}$. Mónica Morales - Ramírez ${ }^{1} \cdot$ Andrea Rivera - Cavazos $^{1}$
}

Published online: 17 April 2021

(C) Springer Nature Switzerland AG 2021

\section{Correction to: SN Comprehensive Clinical Medicine https://doi.org/10.1007/s42399-021-00875-7}

The original article unfortunately contained an error. The last author, Andrea Rivera - Cavazos, was not added in the article.

The original article has been corrected.

Publisher's Note Springer Nature remains neutral with regard to jurisdictional claims in published maps and institutional affiliations.

The online version of the original article can be found at https://doi.org/ 10.1007/s42399-021-00875-7

\footnotetext{
Azucena Maribel Rodríguez - González azucena1078@gmail.com

1 Universidad de Monterrey, Monterrey, Nuevo León, México

2 Universidad de Monterrey, Av. Ignacio Morones Prieto 4500 Pte. Col. Jesús M. Garza, CP 66238 San Pedro Garza García, N.L., México

3 Hospital Universitario Dr. José E. González, Monterrey, Nuevo León, México
} 